\title{
IDENTIFYING STRESS SIGNATURES ACROSS THE ENGINEERING DESIGN PROCESS: PERCEIVED STRESS DURING CONCEPT GENERATION, CONCEPT SELECTION, AND PROTOTYPING
}

\author{
H. Nolte and C. McComb ${ }^{\otimes}$ \\ The Pennsylvania State University, United States of America \\ $\bigotimes$ uum209@psu.edu
}

\begin{abstract}
Various aspects of the design process often lead to stress. This study used pre- and post-task surveys to gather information regarding the designer's cognitive experience, physiological response, and perceived sources of stress during concept generation, concept selection, and prototyping. Results confirmed that design is highly cognitive, and that mental stress is present. Variability in the results also suggests that a physiological stress component might be present. Additionally, perceived sources of stress were examined, and recommendations were offered for instructors of design courses.
\end{abstract}

Keywords: design education, stress in design, human behaviour, design process

\section{Introduction and related work}

Work-related stress is widespread; specifically, an increase in work-related stress has been observed in engineering consultants (Ipsen and Jensen, 2012). Engineering students also experience a significant level of stress which has been identified as a predictor for negative health measures (Foster and Spencer, 2003). Engineering professionals and students can be typified as knowledge workers (workers in knowledge-intensive positions), relying on their strong knowledge base and cognitive skills to accomplish difficult problem-solving tasks. High-level cognitive skills are especially important in the field of engineering design (Alexiou et al., 2009), which leverages a number of complex cognitive processes (Alexiou et al., 2009; Dinar et al., 2015). The requisite cognitive complexity found in design is largely driven by design problems which are constantly evolving, ambiguous, and influenced by both internal and external pressures (Dym et al., 2005; Kana et al., 2016). All of these factors potentially contribute to the stress experience of design engineers.

Though increased stress has been observed in engineering professionals and students (Foster and Spencer, 2003; Ipsen and Jensen, 2012), little research has examined what aspects of engineering are contributing to that increase in stress. While the stress of professionals and students can be influenced by many contextual factors (Dunkel-Schetter and Lobel, 1990; Gee et al., 1987), it is more probable that increased stress is caused by the relatively new demands of engineering work. The skills required for modern engineering are not the same set of skills that were required of traditional engineers in the past (Alblawi et al., 2019; Tryggvason and Apelian, 2006). For example, there is an increased focus in engineering education on developing more abstract skills like innovation and creativity to better prepare students for 21st century engineering (Spinks et al., 2006; Tryggvason and Apelian, 2006). The presence 
of stress in knowledge workers (Ipsen and Jensen, 2012) suggests that workers in cognitively heavy professions, like engineering, may experience high levels of stress due to the nature of their work. Therefore, it is likely that designers would also experience high levels of stress due to the primarily cognitive focus of their work. This is underscored by the fact that abstract and cognitive skills have been shown to be core abilities for good designers (Dym et al., 2005).

While much research has examined methods to make engineers better designers (Akhavi and Hayes, 2007; Lukszo and Heijnen, 2007) only recently have studies started to investigate the cognitive experience of engineers during design (Nguyen and Zeng, 2014, 2017; Tang and Zeng, 2009). Understanding the cognitive process of design is incredibly important because recent research suggests that engineering design induces mental stress in engineers that persists even after the design task is completed (Nguyen and Zeng, 2017). Repeated design projects throughout a career may lead to chronic mental stress in designers, which could have serious long-term health implications. Mental stress in design can also effect an engineer in a variety of other ways, including changes to their levels of creativity and motivation (Håkansson and Törlind, 2014; Nguyen and Zeng, 2012, 2017). It is suggested that some stress is required for engineers to be motivated and engaged in a design project but that too much stress during the task may become oppressive (Håkansson and Törlind, 2014). Nguyen and Zeng (2012) predict that creativity is similarly affected by stress, leading to a U-shaped graph in which creativity is low when stress is low or high and creativity is high when stress is at a medium level. Conversely, one study suggest that individual differences, like personality, mediate how stress effects creativity in designers (García-García et al., 2019). In this way, stress is inescapable and also inextricably linked to performance.

Work-related stress can have serious negative health consequences and up to $40 \%$ of workers experience work related stress often or very often (Control et al., 1999). Stress, particularly chronic stress (repetitive stress over a period of time), has been linked to slowed recovery, higher susceptibility to infections and incurable diseases, lowered immunity, and greater likelihood of cardiovascular issues (Sharma and Gedeon, 2012). Associated healthcare costs for work-related stress in the United States are conservatively estimated to be \$125 billion USD annually (Goh et al., 2016). This equates to over $\$ 1000$ USD per worker per year and up to $8 \%$ of the total annual healthcare costs in the United States (Goh et al., 2016). Work-related stress costs up to $\$ 580.32$ million in Australia, \$2.27 billion in Denmark, \$4.36 billion in France, and \$703.12 million in Sweden (Hassard et al., 2018). Workplace stress also contributes to more than 120,000 unnecessary deaths in the United States, making the issue comparable to the fourth largest leading cause of death in the United States (Goh et al., 2016).

Not only does chronic work stress have major health consequences, but it is also a leading cause of burnout (Salvagioni et al., 2017). Burnout has been associated with increased sleep disturbances, insomnia, a higher likelihood of depression and depressive symptoms, exhaustion, cynicism and diminished sense of personal accomplishment (Lingard, 2003; Salvagioni et al., 2017). Cynicism and emotional exhaustion were strong predictors of whether engineers intended to leave their jobs (Lingard, 2003). It has been estimated that burnout costs United States businesses \$300 billion USD annually (American Institute of Stress, 2018). In addition, it is approximated that as much as $90 \%$ of the total cost of workplace stress is associated with losses in worker productivity, which have not been directly quantified yet (Hassard et al., 2018).

The current study focuses on identifying the stress signatures experienced by engineering students during concept generation, concept selection, and prototyping. Previous literature has demonstrated that mental stress occurs throughout the design process (Nguyen and Zeng, 2017) but it is unknown how each component (i.e., skill) of the design process contributes to the stress signature. Assessing the design process as a whole does not provide sufficient nuance on which to construct stress-mitigating interventions. Towards this end, we address three research questions in the current work:

1. Do subjective cognitive, perceived, and physiological responses vary in response to different skills used during the design process? If so, what are the unique stress signatures of these tasks?

2. Does engineering design induce perceivable physiological changes due to stress?

3. Do students rank perceived sources of stress differently for each design task? 
Answering these questions will lead to a deeper understanding of the designer's experience, which is crucial to making the design process as effective as possible. Most engineers will go through the design process hundreds of times throughout their career and it is important to understand the experience and stress associated with the design process because stress has many negative long-term health side effects. If the points and characteristics of stress during the design process were understood, design could be taught with those points in mind, stress of designers could be limited, and quality of final products from design could be improved.

\section{Methodology}

In the current study, three separate design tasks were developed for concept generation, concept selection, and prototyping. These three skills were chosen because they are principal components of the engineering design process (Dieter and Schmidt, 2012). Data on the stress experience during these tasks was collected using pre- and post-task surveys.

\subsection{Participants}

The experimental tasks were completed by introductory engineering students at The Pennsylvania State University. The three tasks were completed as in-class exercises during a required introductory engineering design course intended to provide students with a foundation for engineering design through hands-on team projects that address specified design opportunities. All students were previously taught concept generation, concept selection, and prototyping in the course before participating in this study. A total of 25 students participated in this within-subjects study. Due to student absences 25 students completed concept generation, 22 students completed concept selection, and 21 students completed the prototyping task. Of the students who entered the study, 19 were 18 years old and 6 were 19 years old, 19 were male and 6 were female, and 19 identified as white and 6 identified as a minoritized race.

\subsection{Procedure}

All students signed a written consent form prior to participating in the study in accordance with institutional review board protocol. All three engineering design tasks were completed individually by participants during three separate class sessions, and class sessions were not scheduled back-toback. Each data collection session was no more than 30 minutes in duration. Before starting each design task, students watched a short video (less than five minutes) detailing the life of a prominent engineer (one video was watched per data collection session). The videos served as a resting activity during which participants' stress state stabilized. Previous research has confirmed the viability of using a video for the purpose of a resting activity (Piferi et al., 2000). Videos were carefully chosen to avoid priming students with respect to the activities involved in the subsequent task. After completing the resting activity, students completed a pre-task survey that included a modified version of the raw NASA-Task Load Index (NASA-RTLX) (Hart and Staveland, 1988, 2006) and the Physiological Arousal Questionnaire (PAQ) developed by Kallen (2002). Previous research suggests that as mental workload increases (measured using the NASA-TLX), stress also increases and physiological signs become more prevalent (Fallahi et al., 2016). In addition to the NASARTLX, three extra questions queried how stressed, discouraged, and insecure participants were feeling due to the task. The NASA-TLX includes these additional measures in the description of frustration. These questions were added to obtain a more detailed understanding of the designer's cognitive experience. To prevent participants from matching their answers for the additional questions to their answer for frustration, the additional questions were queried before the sixth measure of the NASA-RTLX (frustration). A specific survey for participants' state stress was not including in this study to prevent over surveying during a short time period and because it was undetermined whether introductory engineering design students would experience cognitive stress across all aspects of the design process. All survey questions were structured to match the formatting of the NASA-RTLX.

After completing the pre-task survey students were given instruction for the design task. All design tasks were ten minutes in duration to prevent time from influencing one task more than another. 
During pilot studies, the complexity of each of the tasks was tuned to match this amount of time. A display showing the time remaining for the task was always visible in the front of the room to allow participants to manage their own time during the task. To ensure that the task prompts used for earlier design tasks did not bias later design tasks, three different, unrelated design task prompts were used. After each design task, students completed a post-task survey. The post-task survey consisted of the NASA-RTLX (Hart and Staveland, 1988) with the three additional questions, the PAQ (Kallen, 2002), a free response question querying if they used any coping mechanism during the task and if so which ones, and a section in which students could rank their top five sources of stress from a provided list of stressors developed while piloting this study.

Tasks were derived from previous uses in the literature. The first design task was concept generation, in which students were asked to brainstorm as many ideas as they could to allow employees in a company to exercise and work at the same time (Nguyen and Zeng, 2017). The students completed the post-task survey after the completion of time. The second task was concept selection. Students were given six designs for accessible drinking fountains (Goldschmidt and Smolkov, 2006; Goucher-Lambert et al., 2019) and they were asked to complete a decision matrix (Pugh, 1991) which accounted for various aspects of accessibility. Students were also asked to choose the best and worst design. After the completion of time, students completed the post-task survey. During the third task students were asked to prototype a provided design for a device to immobilize the knee (Goucher-Lambert et al., 2019; Wilson et al., 2010). Students were given the ten minutes to create and test the prototype using paper and tape. After the completion of time, students were asked questions about their prototyping experience. Upon conclusion of the prototyping survey, students completed the post-task survey.

\section{Results and discussion}

Results are discussed across four subsections: results that are specific to each of the task types; results regarding the modified NASA-RTLX; results on the perceived sources of stress; and results on the PAQ.

\subsection{Task-specific results}

No pre-task differences were found for any of the modified NASA-RTLX or PAQ measures when Mann-Whitney $U$ tests were used to compare concept generation, concept selection, and prototyping. During concept generation, students were given the option to sketch, write descriptions, or both sketch and write to portray their ideas. A linear regression model was used to find predictors of the number of ideas generated by students during the concept generation task. The number of predictors in the model was limited due to small sample size and power; method used to convey ideas was chosen as a predictor due to its significance in previous research (Neumann et al., 2009) and post-task stress and discouragement were used as predictors because they had the highest posttask means (Figure 1) out of the four psychological measures in the NASA-RTLX (i.e. stress, discouragement, insecurity and frustration). In this model, method used to convey ideas and posttask stress were both identified as significant predictors; $\mathrm{F}(3,21)=3.684, \mathrm{P}<0.5$, Adjusted $\mathrm{R}^{2}=$ $25.12 \%$. This suggests that the method used to convey ideas and the amount of stress experienced during concept generation both effect the number of ideas generated by students during a concept generation task. Previous literature has demonstrated that sketching ideas can lead to a larger quantity of ideas (Neumann et al., 2009).

During concept selection, students were asked to select the best and worst design after being told that their selections may or may not match the results of the decision matrix. When choosing the best design, 15 students chose the design that had the highest rating in the decision matrix while 6 students chose a design that did not have the highest rating in the decision matrix. When choosing the worst design, 19 students chose the design that had the lowest rating in the decision matrix while 3 students chose a design that did not have the lowest rankings in the decision matrix. These results both suggest that students consider aspects outside the decision matrix when choosing a best or worst design. This aligns with prior work in which students were observed to introduce objectives not explicitly included 
in problem statements (Menold et al., 2018). Instructors should help students identify their inherent biases regarding idea quality to improve their ability to objectively judge designs.
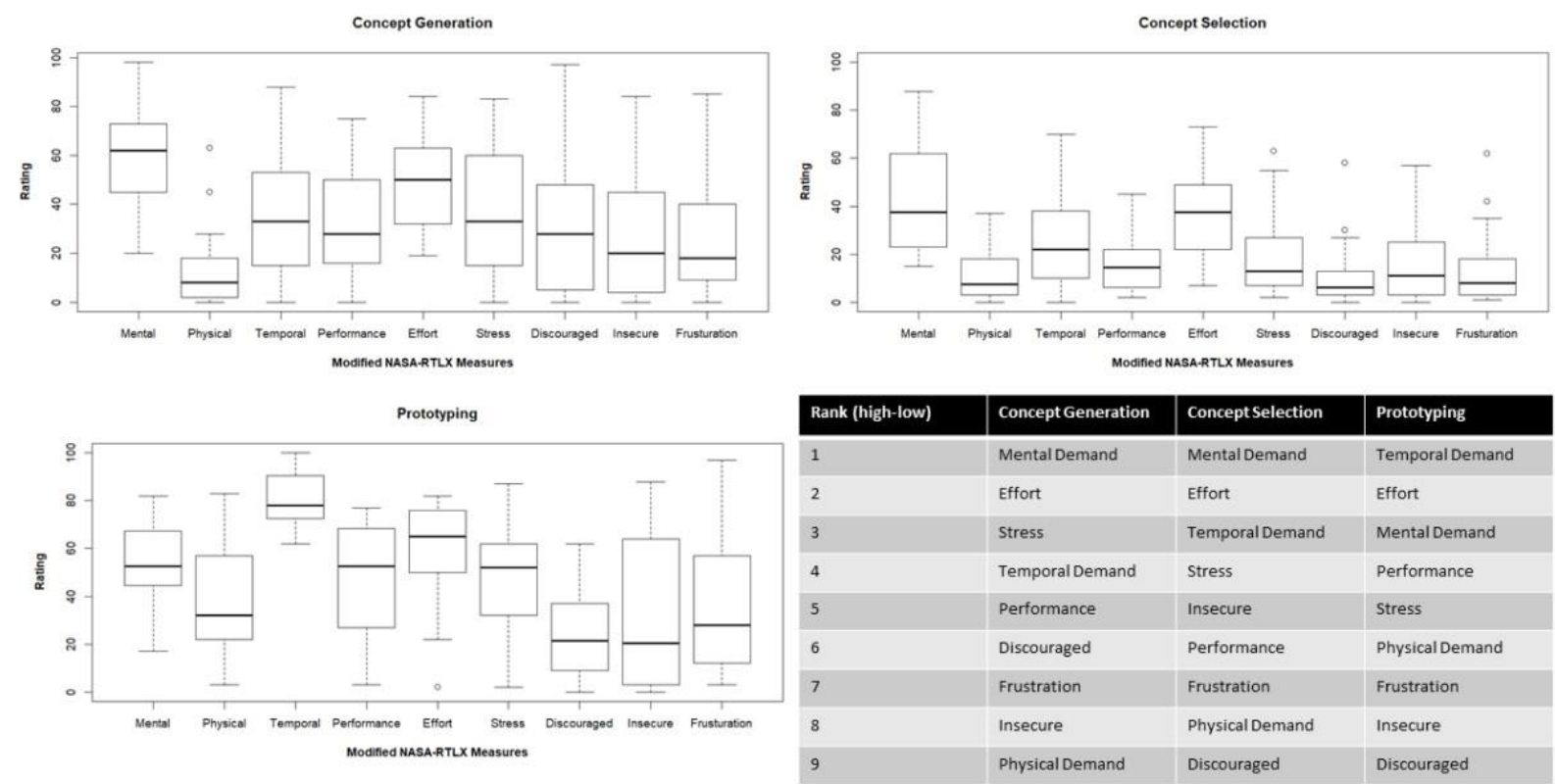

Figure 1. Modified NASA-RTLX post-task measures and ranking

After prototyping the given design, students were asked various questions about their prototyping experience. When asked about prototype completion, 5 students reported that they were able to completely finish the prototype, and 16 students reported that they were not able to. A mean difficulty of 5.71 ( $\mathrm{SD}=1.45$ ) was reported when students were asked how easy the prototype was to build (a 10 point scale was used, bounded by very easy to extremely difficult). This moderate perceived difficulty level suggests that a different factor likely contributed to the low completion fraction. When asked if they made a mistake during the prototyping task, 6 students reported that they did not, and 15 students reported that they did. The high number of mistakes made during the prototyping task suggests that prototyping may be a more novel concept for introductory engineering students compared to concept generation and concept selection. To ensure that students understand the concept well, instructors should provide students with various prototyping tools and the chance to complete multiple prototyping activities (Lauff et al., 2019; Menold et al., 2019).

\subsection{Modified NASA-RTLX}

All post-task modified NASA-RTLX measures are shown in Figure 1. Each task (i.e., concept generation, concept selection, and prototyping) has unique post-task modified NASA-RTLX results. It is confirmed that design is a highly cognitive process (Alexiou et al., 2009; Dinar et al., 2015) because high rankings for mental demand and effort occurred for all three tasks.

Although it is not meaningful to directly compare the NASA-RTLX results between such disparate tasks, the ranking of NASA-RTLX measures is suitable for inter-task comparison (see Figure 1). Stress is ranked 3rd for concept generation, 4th for concept selection, and 5th for prototyping, suggesting that mental stress is experienced throughout the design process at varying levels. This affirms that studying the stress experience across an entire design is insufficient for understanding how stress is experienced during the design process. However, it should be noted that stress decreases in ranking across the design process. In contrast, temporal demand increases in ranking from concept generation (4th) to concept selection (3rd) to prototyping (1st). Previous literature has shown that over half of all appropriate ideas are generated within the first ten minutes of ideation session (Howard et al., 2008) which would align with lower temporal demand during concept generation. Higher temporal demand during prototyping may suggest that time-constrained prototyping activities induce a different cognitive experience than 
traditional prototyping due to the increased temporal demand. Frustration, discouragement, and insecurity were rated low in all three tasks.

\subsection{Perceived sources of stress}

Students ranked their top five perceived sources of stress from a list of 20 sources of stress developed while piloting this study. Little information was observable in the choice of fourth and fifth perceived sources of stress, so the top three sources of stress are summed for each task and presented in Table 1.

Table 1. Perceived sources of stress. The top source of stress for each task is asterisked

\begin{tabular}{|l|l|l|l|l|}
\hline Perceived Source & Concept Generation & Concept Selection & Prototyping & Total \\
\hline More than enough time & 8 & 8 & 0 & 16 \\
\hline Materials were difficult to use & 0 & 0 & 14 & 14 \\
\hline Instructions were hard to follow & 0 & 1 & 0 & 1 \\
\hline I did not know what I was doing & 1 & 1 & 3 & 5 \\
\hline Task brief was restricting & 3 & 1 & 2 & 6 \\
\hline Too many ideas & 1 & 2 & 0 & 3 \\
\hline Task brief was vague & 5 & 2 & 2 & 9 \\
\hline I could not choose one & 2 & $12^{*}$ & 0 & 14 \\
\hline I thought of a better idea & 2 & 1 & 0 & 3 \\
\hline I was uninterested in the task & 9 & 5 & 2 & 16 \\
\hline I was nervous & 2 & 0 & 1 & 3 \\
\hline Not enough ideas & $17 *$ & 1 & 1 & 19 \\
\hline Brief was confusing & 0 & 3 & 1 & 4 \\
\hline I made a mistake & 1 & 2 & 4 & 7 \\
\hline The task was too easy & 2 & 4 & 1 & 7 \\
\hline The task was too hard & 1 & 0 & 2 & 3 \\
\hline The instructions were confusing & 1 & 3 & 1 & 5 \\
\hline I got stuck on one thing & 6 & 8 & 7 & 21 \\
\hline Not enough information was given & 6 & 8 & 0 & 14 \\
\hline Not enough time & 5 & 4 & $19 *$ & 28 \\
\hline & & & & \\
\hline
\end{tabular}

The top perceived stressor for concept generation was not having enough ideas, indicating students preexisting bias towards idea fluency. Many students also reported having too much time as a stressor. This result matches the results seen in the modified NASA-RTLX of the temporal demand being low, although some students also reported not having enough time. In order to decrease stress during concept generation, instructors may want to remind students that there is no prescribed number of solutions a designer should generate and that they may or may not use all the time allotted to them. Instructors should also bear in mind, and communicate to their students, that all students are different, and some may take longer than others to complete a concept generation task. The concept generation results also indicate that some students prefer more detailed task briefs (other common stressors included task brief was too vague and not enough information is given). To mitigate this source of stress, instructors may need to teach students strategies for handling this ambiguity, commonly seen within design problems (Adams et al., 2003; Dringenberg and Wertz, 2016). Students also reported getting stuck on one thing, for which instructors may want to provide approaches to overcoming fixation. Design fixation during concept generation is a complex phenomenon, but many methods, such as product dissection, have been explored to mitigate its negative effects (Toh et al., 2014).

During concept selection there was again a mix of students who reported that they had too much time and students who reported not having enough time. Similar to concept generation, many students reported getting stuck on one thing and they also reported that they could not choose one (this was the top perceived stressor for concept selection). Strategies should be explored, taught, and practiced to help students with these situations. It should be noted that a Pugh chart, which is commonly used to support concept selection, was provided to students in template form for this task. Therefore, it may be necessary for instructors to teach additional reasoning skills. Ambiguity also caused some students to 
be stressed during concept selection (not enough information was given, and task brief was too vague). There was more confusion during concept selection compared to the other two tasks. This may be due to the individual task brief, but this should be confirmed in future research.

The top stressor for prototyping was not having enough time. One interpretation of this result is that instructors should ensure that students have ample time to finish prototyping tasks and are not unduly stressed by time constraints. Another interpretation is that instructors should actively educate their students on time management techniques for both cognitive and physical tasks. Students also reported being stressed because the materials were difficult to use. To mitigate this source of stress, instructors should expose students to various materials for this work through a variety of prototyping activities. Previous stressors observed in concept generation and concept selection were also observed with prototyping, namely getting stuck on one thing. Strategies for preventing fixation during prototyping (Walker et al., 2010) should be introduced by instructors. There was an increase in students who did not know what they were doing. This again suggests that prototyping is a more novel skill in comparison to concept generation and concept selection and that extra consideration should be given when teaching the topic. Fewer students reported being uninterested in the task as a perceived stressor for prototyping compared to concept generation and concept selection. This may be due to the topic of the task brief or to the more hands-on nature of the task, and further research should try to determine the cause.

\subsection{Physiological results}

The difference between the pre-task and post-task PAQ measures for each task are plotted in Figure 2. The PAQ queries nine items including warm/sweaty hands, sweating, feeling your heart beating, feeling hot/short of breath, dry mouth, tingling sensation in your face/hands, and nervousness (Kallen, 2002). Very little change in the means of the physiological index measures was observed. There are some differences in the $75^{\text {th }}$ percentile for certain PAQ measures, especially during prototyping (Figure 2). This may be due to the low stress of the activities, the duration of the task being too short to induce noticeable physiological stress, or the difficulty of the participants in noticing physiological changes due to the mainly cognitive nature of the task. Future research should use wearable sensors to obtain a more objective physiological response for all tasks.

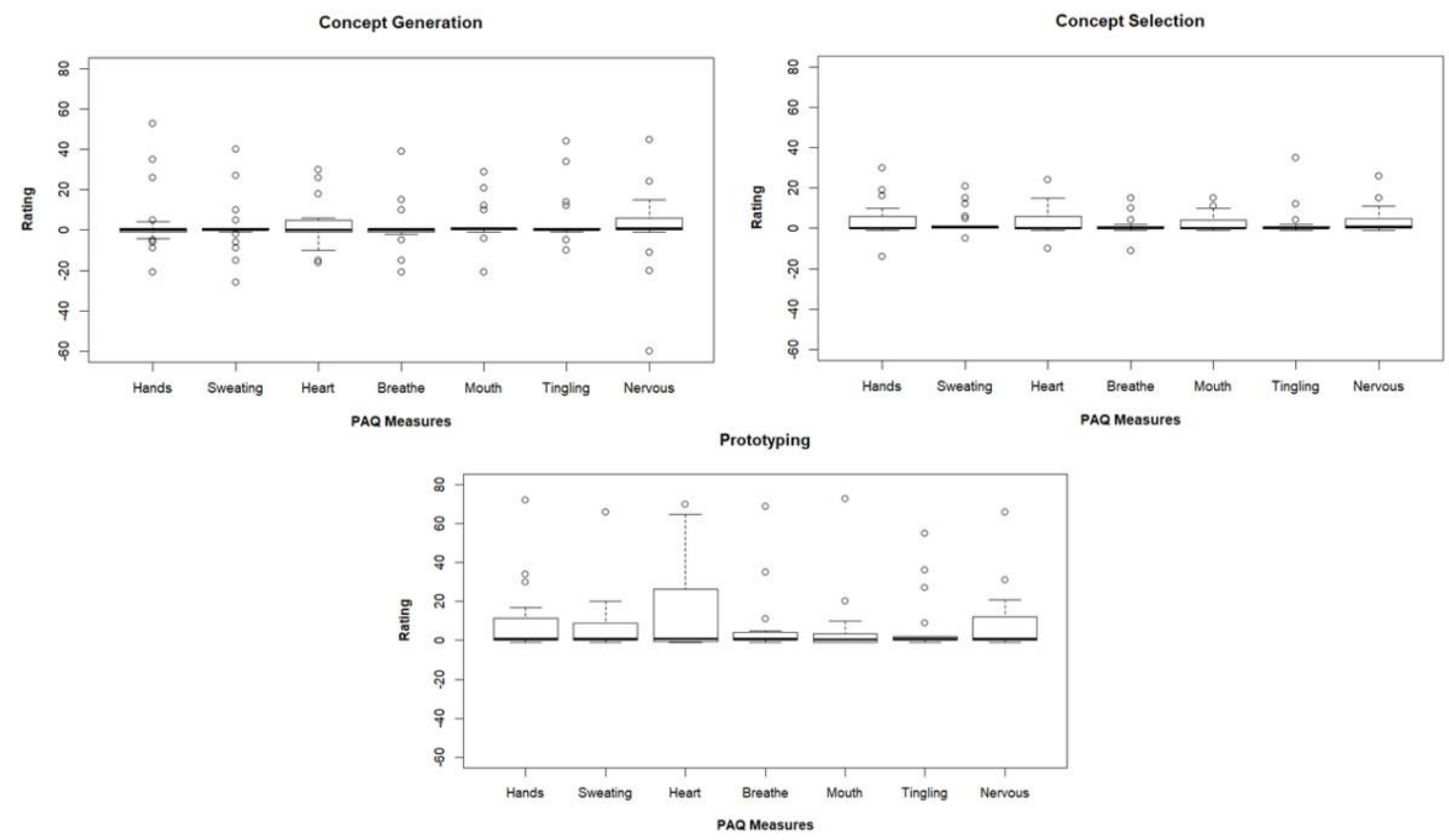

Figure 2. Pre-task and post-task differences for modified NASA-RTLX

The spread of responses was much smaller for concept generation compared to concept selection and prototyping. Concept selection and prototyping have more variability for certain measures compared to concept generation, especially for heart rate during the prototyping task. The larger variability in response may suggest that a physiological response is occurring for some individuals. 
This is further supported by the fact that several of the outliers originate from the same individuals. This may underscore the individual nature of stress response that is predicated on background and cognitive state.

\section{Future work}

This study is limited by the relatively small and homogenous (in terms of race, gender, and age) sample. These results, however, are promising and warrant further investigation into the cognitive experience of designers during the design process. Since stress was present across all three tasks, a survey examining the state stress of the participants' could be used in the future to better understand what components of stress are prevalent in the stress signature of each task (e.g., the Short Stress State Questionnaire (Helton, 2004)). This study should be replicated with not only introductory students, but upper level students and professionals to understand if the perceived sources of stress change with experience. Individual differences of the students should also be explored as predictors of stress experience (e.g., gender, race, age, cognitive style). Although the current results suggest that a physiological response may be present, this information is based on qualitive and selfreported measures. Therefore, a future replication study should also include wearable physiological sensors to capture a more reliable, objective measure of the physiological stress response. The duration of the tasks should also be adapted to better understand how the duration of the task effects the cognitive load and the stress response. Future work should leverage a variety of task topics and briefs to ensure that the results being observed are not due to the topic (e.g., accessible water fountains) but due to the task (e.g., concept selection).

\section{Conclusion}

Design is a highly cognitive and complex process (Alexiou et al., 2009; Dinar et al., 2015) with problems that are often complicated and abstract (Dym et al., 2005; Kana et al., 2016). Highly cognitive tasks, such as those found in design, can cause stress (Ipsen and Jensen, 2012), which has been linked to negative health consequences (Sharma and Gedeon, 2012). Little research has been conducted to understand the cognitive experience of designers. This study explored the task-induced stress experience of introductory engineering students during concept generation, concept selection, and prototyping.

Differences in the modified NASA-RTLX measures were present for each task and confirmed that design is highly cognitive (Alexiou et al., 2009; Dinar et al., 2015). Modified NASA-RTLX measures also suggest that stress is present during all three tasks. In addition, perceived sources of stress were examined for each task and recommendations were offered for instructors of design courses or courses with a design component. No significant changes were found for the PAQ items, but increased variability suggests that there might be a physiological stress component in addition to the self-reported stress component; further research is needed to confirm this. A more comprehensive understanding of the designer's cognitive experience can lead to better teaching/reteaching of design, mitigate negative health consequence and burnout, and lead to more productive designers.

\section{References}

Adams, R.S., Turns, J. and Atman, C.J. (2003), "Educating effective engineering designers: the role of reflective practice”, Design Studies, Vol. 24 No. 3. https://doi.org/10.1016/S0142-694X(02)00056-X

Akhavi, F. and Hayes, C.C. (2007), "Decision making in engineering design tasks: Do designers benefit from representations of uncertainty?", 51st Annual Meeting of the Human Factors and Ergonomics Society, HFES. https://doi.org/10.1177/154193120705100447

Alblawi, A., Nawab, M. and Alsayyari, A. (2019), "A system engineering approach in orienting traditional engineering towards modern engineering", IEEE Global Engineering Education Conference, EDUCON. https://doi.org/10.1109/EDUCON.2019.8725097

Alexiou, K. et al. (2009), "Exploring the Neurological Basis of Design Cognition Using Brain Imaging: Some Preliminary Results", Design Studies. https://doi.org/10.1016/j.destud.2009.05.002

American Institute of Stress (1 January 2018), Workplace Stress. https://doi.org/10.26616/NIOSHPUB99101

Control, C. for D. et al. (1999), Stress ...at Work. https://doi.org/10.26616/NIOSHPUB99101 
Dieter, G. and Schmidt, L. (2012), Engineering Design, 5th Edition., McGraw Hill, Boston.

Dinar, M. et al. (2015), "Empirical Studies of Designer Thinking: Past, Present, and Future", Journal of Mechanical Design, Vol. 137, p. 2. https://doi.org/10.1115/1.4029025

Dringenberg, E. and Wertz, R.E.H. (2016), "How do first-year engineering students experience ambiguity in engineering design problems: The development of a self-report instrument", ASEE Annual Conference and Exposition. https://doi.org/10.18260/p.25474

Dunkel-Schetter, C. and Lobel, M. (1990), "Stress among students", New Directions for Student Services, Vol. 1990 No. 49. https://doi.org/10.1002/ss.37119904904

Dym, C.L. et al. (2005), "Engineering design thinking, teaching, and learning", Journal of Engineering Education, Vol. 94, p. 1. https://doi.org/10.1109/EMR.2006.1679078

Fallahi, M. et al. (2016), "Effects of mental workload on physiological and subjective responses during traffic density monitoring: A field study", Applied Ergonomics, Elsevier Ltd, Vol. 52. https://doi.org/10.1016/ j.apergo.2015.07.009

Foster, C. and Spencer, L. (2003), "Are undergraduate engineering students at greater risk for heart disease than other undergraduate students?", Journal of Engineering Education, Wiley-Blackwell Publishing Ltd, Vol. 92 No. 1. https://doi.org/10.1002/j.2168-9830.2003.tb00740.x

García-García, C. et al. (2019), "Does the work environment affect designers' creativity during the creative phase depending on their personality profile?", Thinking Skills and Creativity, Elsevier Ltd, Vol. 33. https://doi.org/10.1016/j.tsc.2019.100578

Gee, G.W.M., Goodson, J.R. and Cashman, J.F. (1987), "Job Stress and Job Dissatisfaction: Influence of contextual factors", Psychological Reports, Vol. 61. https://doi.org/10.2466/pr0.1987.61.2.367

Goh, J., Pfeffer, J. and Zenios, S.A. (2016), "The Relationship Between Workplace Stressors and Mortality and Health Costs in the United States", Management Science, INFORMS, Vol. 62 No. 2. https://doi.org/ $10.1287 / \mathrm{mnsc} .2014 .2115$

Goldschmidt, G. and Smolkov, M. (2006), "Variances in the impact of visual stimuli on design problem solving performance", Design Studies, Vol. 27 No. 5. https://doi.org/10.1016/j.destud.2006.01.002

Goucher-Lambert, K., Moss, J. and Cagan, J. (2019), “A Neuroimaging Investigation of Design Ideation with and without Inspirational Stimuli-Understanding the Meaning of near and Far Stimuli", Design Studies. https://doi.org/10.1016/j.destud.2018.07.001

Håkansson, A. and Törlind, P. (2014). Enhancing student motivation - 'raise the bar'”, 16th International Conference on Engineering and Product Design Education: Design Education and Human Technology Relations, E and PDE 2014, Institution of Engineering Designers, The Design Society, pp. 414-419.

Hart, S.G. and Staveland, L.E. (1988), "Development of NASA-TLX (Task Load Index): Results of emperical and theoretical research", Human Mental Workload, Vol. 1 No. 3. https://doi.org/10.1016/S01664115(08)62386-9

Hart, S.G. and Staveland, L.E. (2006), “NASA-Task Load Index (NASA-TLX): 20 years later”, Human Factors and Ergonomics Society Annual Meeting, Vol. 50 No. 9. https://doi.org/10.1177/154193120605000909

Hassard, J. et al. (2018), "The cost of work-related stress to society: A systematic review", Journal of Occupational Health Psychology, Vol. 23 No. 1. https://doi.org/10.1037/ocp0000069

Helton, W.S. (2004), "Validation of a Short Stress State Questionnaire", Human Factors and Ergonomic Society. https://doi.org/10.1177/154193120404801107

Howard, J.T., Culley, S.J. and Dekoninck, E. (2008), "Idea generation in conceptual design", DESIGN 2008, the 10th International Design Conference, pp. 1025-1032.

Ipsen, C. and Jensen, P.L. (2012), "Organizational options for preventing work-related stress in knowledge work", International Journal of Industrial Ergonomics, Vol. 42, p. 4. https://doi.org/10.1016/j.ergon.2012.02.006

Kallen, V.L. (2002). "Physiological Arousal Questionnaire", Department of Child and Adolescent Psychiatry, Erasmus Medical Center, Rotterdam.

Kana, A.A., Shields, C.P.F. and Singer, D.J. (2016). "Why is naval design decision-making so difficult?", RINA, Royal Institution of Naval Architects - International Conference on Warship 2016: Advanced Technologies in Naval Design, Construction, and Operation, Royal Institution of Naval Architects.

Lauff, C., Menold, J. and Wood, K.L. (2019), Prototyping Canvas: Design Tool for Planning Purposeful Prototypes. https://doi.org/10.1017/dsi.2019.162

Lingard, H. (2003), "The impact of individual and job characteristics on 'burnout' among civil engineers in Australia and the implications for employee turnover", Construction Management and Economics, Vol. 21 No. 1. https://doi.org/10.1080/0144619032000065126

Lukszo, Z. and Heijnen, P. (2007). "Better design and operation of infrastructures through bi-level decision making", 2007 IEEE/ACS International Conference on Computer Systems and Applications, IEEE, Piscataway, NJ, USA, https://doi.org/10.1109/ICNSC.2007.372773 
Menold, J. et al. (2018). “Thus, I had to go with what i had': A multiple methods exploration of novice designers' articulation of prototyping decisions", Proceedings of the ASME Design Engineering Technical Conference, Vol. 7, American Society of Mechanical Engineers (ASME), https://doi.org/10.1115/DETC2018-85800

Menold, J., Jablokow, K. and Simpson, T. (2019), "The Prototype for X Framework: Assessing Impact on SelfReported Prototyping Behavior of Student Designers”, Journal of Mechanical Design, Transactions of the ASME, American Society of Mechanical Engineers (ASME), Vol. 141 No. 4. https://doi.org/10.1115/ 1.4041781

Neumann, A., Badke-Schaub, P. and Lauche, K. (2009), "Show me what you've got: The influence of combined sketching on idea generation in teams", ICED 09, the 17th International Conference on Engineering Design, pp. 191-198.

Nguyen, T.A. and Zeng, Y. (2012), “A Theoretical Model of Design Creativity: Nonlinear Design Dynamics and Mental Stress-Creativity Relation", Transactions of the SDPS: Journal of Integrated Design and Process Science, Vol. 16, p. 3. https://doi.org/10.3233/jid-2012-0007

Nguyen, T.A. and Zeng, Y. (2014), “A physiological study of relationship between designer's mental effort and mental stress during conceptual design", Computer-Aided Design, Elsevier, Springer US, Vol. 54. https://doi.org/10.1016/J.CAD.2013.10.002

Nguyen, T.A. and Zeng, Y. (2017), "Effects of stress and effort on self-rated reports in experimental study of design activities", Journal of Intelligent Manufacturing, Vol. 28 No. 7, pp. 1609-1622.

Piferi, R.L. et al. (2000), “An alternative approach for achieving cardiovascular baseline: Viewing an aquatic video", International Journal of Psychophysiology, Vol. 37 No. 2. https://doi.org/10.1016/S01678760(00)00102-1

Pugh, S. (1991), Total Design: Integrated Methods for Successful Product Engineering, Addison-Wesley.

Salvagioni, D.A.J. et al. (2017), "Physical, psychological and occupational consequences of job burnout: A systematic review of prospective studies", PLOS ONE, Vol. 12 No. 10. https://doi.org/10.1371/ journal.pone. 0185781

Sharma, N. and Gedeon, T. (2012), "Objective measures, sensors and computational techniques for stress recognition and classification: A survey", Computer Methods and Programs in Biomedicine, Elsevier, Vol. 108 No. 3. https://doi.org/10.1016/J.CMPB.2012.07.003

Spinks, N., Silburn, N. and Birchall, D. (2006), Educating Engineers for the 21st Century: The Industry View, Royal Academy of London, Oxfordshire, UK.

Tang, Y. and Zeng, Y. (2009), “Quantifying Designer's Mental Stress During the Conceptual Design Process Using Kinesics Study”, International Conference on Engineering Design, ICED'09, pp. 211-219.

Toh, C., Miller, S. and Kremer, G. (2014), "Mitigating Design Fixation Effects in Engineering Design Through Product Dissection Activities", In: Design Computing and Cognition '12, Springer, Netherlands. https://doi.org/10.1007/978-94-017-9112-0_6

Tryggvason, G. and Apelian, D. (2006), "Re-Engineering Engineering Education for the Challenges of the 21st Century", Journal of the Minerals, Metals, and Materials Society, Vol. 58 No. 10, pp. 14-17.

Walker, V. et al. (2010), "Effects of an early prototyping experience on the innovation process: Can design fixation be avoided?", ASEE Annual Conference and Exposition.

Wilson, J.O. et al. (2010), "The effects of biological examples in idea generation", Design Studies, Vol. 31 No. 2. https://doi.org/10.1016/j.destud.2009.10.003 